\title{
La contradicción entre capitalismo y democracia: hacia una nueva perspectiva emancipatoria
}

\author{
The contradiction between capitalism and democracy: towards a \\ new emancipatory perspective
}

\section{Facundo Nahuel Martín \\ Martín Ariel Mosquera}

\section{Resumen}

Diversos autores en las últimas décadas consolidaron una fuerte "crítica democrática" al marxismo. En este trabajo nos concentraremos en las obras de Ernesto Laclau y Chantal Mouffe, por un lado, y Axel Honneth, por el otro, quienes cuestionan al marxismo desde perspectivas que pretenden reconstruir la reorganización de las relaciones sociales que emerge con la modernidad. Nuestro objetivo es mostrar que la concepción del Estado de Antoine Artous permite reformular en términos marxistas la contradicción entre capitalismo y democracia de un modo que habilita, a la vez, reconstruir los procesos de ampliación de derechos en la modernidad y abrir un proyecto anticapitalista nototalizante, desvinculado de lo que llamaremos "concepción orgánica" de la emancipación. La metodología de trabajo para esto, tratándose de un texto teórico, es la exégesis de textos y la confrontación de hipótesis de lectura.

\section{Palabras clave}

Capitalismo; Demoracia; Honneth; Laclau; Artous.

\begin{abstract}
Various authors through the last decades consolidated a strong "democratic critique" of Marxism. In this paper we will focus on the works of Ernesto Laclau and Chantal Mouffe, on one hand, and Axel Honneth, on the other, who question Marxism from perspectives that seek to reconstruct the reorganization of social relations that emerge with modernity, the "democratic revolution" and modern law. Our objective is to show that the State derivation theory of Antoine Artous allows reformulating in Marxist terms the contradiction between capitalism and democracy. This would, at the same time, reconstruct the processes of extending rights in modernity and open a non-totalizing anti-capitalist project different from what we will call the "organic conception" of emancipation. Since our work is mainly theoretical, our methodology will be the interpretation of texts and the confrontation of reading hypotheses.
\end{abstract}

\section{Keywords}

Capitalism; Democracy; Honneth; Laclau; Artous. 


\section{Introducción}

La historia del marxismo, puede decirse, es la historia de sus crisis y reformulaciones (ROGGERONE, 2018). Las crisis sucesivas de la tradición responden a la necesidad que tiene la crítica radical del capitalismo de reinventarse una y otra vez ante las transformaciones de la realidad histórica, revisando su propio acervo de posiciones heredadas. La crisis actual, que se inicia con la caída de la URSS y se estira hasta nuestros días, está atravesada de cabo a rabo por la cuestión democrática. En efecto, el marxismo como teoría social crítica, como estudio de la sociedad capitalista orientado desde una intencionalidad emancipatoria, necesita un urgente replanteo de sus horizontes emancipatorios tras los desastres totalitarios cometidos en su nombre a lo largo del siglo pasado. La crisis del marxismo actual es multidimensional y se expresa, por lo menos, en tres planos: el cuestionamiento del materialismo histórico como concepción general de la historia universal, la emergencia (o la renovada atención prestada a) una pluralidad de "nuevos movimientos sociales" no organizados inmediatamente en términos de clase (como es el caso de los feminismos, los activismos LGBTQI, los ambientalismos, los movimientos anticoloniales, entre otros) y la sospecha acerca del carácter liberador de una sociedad más allá del capital. Este último punto es especialmente agudo porque indica un "peligro positivo" en el proyecto emancipatorio del marxismo. Acaso soñar con la utopía de un más allá del capital llevaría no a la liberación sino al desastre totalitario, no a una mayor libertad para las personas sino a nuevas formas de opresión.

La crítica democrática al marxismo fue formulada especialmente por ciertos filósofos franceses. Claude Lefort (1990) realizó un planteo paradigmático en "La invención democrática”, señalando que el desastre totalitario sería una consecuencia necesaria de los excesos del proyecto emancipador tal y como fue planteado. Marx pretendería reabsorber toda mediación política en la institución de la sociedad, produciendo una "democracia absoluta" (ABENSOUR, 1998, p. 59) no parasitada ni alienada por las opacidades externas de las formas políticas representativas. Esta vocación absolutizante, sin embargo, conduciría por su propio peso a subsumir a la sociedad en el Estado, antes que a disolver el Estado en la sociedad. La pretensión de erigir una democracia absoluta llevaría al desastre y no a la liberación. El marxismo, entonces, no saldría del siglo solo con las marcas de la derrota (a manos del capital o sus expresiones políticas), sino arrastrando un profundo fracaso intrínseco: el de sus aspiraciones emancipatorias como tales. A lo mejor, el proyecto emancipador que 
buscaba cuestionar a la sociedad capitalista encierra en sí mismo el desastre, y sería mejor producir una crítica no excesiva, no signada por la hybris totalitaria, de la teoría crítica. Frente a las aspiraciones desmesuradas y preñadas de lo peor del "utopismo transfigurativo", parece, sería necesario construir un reformismo social capaz de vérselas con la finitud del sujeto (WHITEBOOK, 1995, p. 21). ${ }^{1}$

Nos concentraremos en las obras de Ernesto Laclau y Chantal Mouffe, por un lado, y Axel Honneth, por el otro, como representantes de diferentes críticas "democráticas" al marxismo que intentan reconstruir teóricamente el movimiento de la modernidad en la "revolución democrática" y el derecho. El marxismo tiene que ocuparse del desafío lanzado por estos pensadores, no solo para reconstruir su ideario emancipatorio en términos más solventes sino también para poder dar cuenta de modo adecuado de la dinámica efectiva de la sociedad moderna y sus conflictos.

Partiendo de concepción del Estado de Antoine Artous volveremos sobre las tesis de Meiksins-Wood (1995) en torno a la contradicción entre capitalismo y democracia. Esta contradicción se despliega en dos sentidos. Primero, informa al proyecto emancipador en una perspectiva destotalizante, capaz de hipotetizar sobre una democracia postcapitalista que amplíe y profundice el terreno de la acción política más allá de las constricciones impuestas sobre ella por el capital. Esta hipótesis emancipatoria no conlleva la hybris totalista propia de las predicciones sobre el fin del Estado y la política o la construcción de una sociedad transparente, absoluta o completamente reconciliada consigo misma. Segundo, esta teoría debe permitirnos comprender críticamente las posibilidades efectivas de la acción en el seno de la sociedad capitalista, los márgenes dentro de los cuales las personas actúan efectivamente en una sociedad que es, en lo fundamental, gobernada por las compulsiones de la acumulación y no por la dinámica política.

\section{Laclau y Mouffe: revolución democrática, liberalismo, socialismo}

Laclau y Mouffe toman como punto de partida el concepto de "revolución democrática” de Claude Lefort y siguen su famosa crítica a Marx (LACLAU y MOUFFE, 2000, p. 174). En "Derechos del hombre y política" (2007), el autor francés formula una crítica a la interpretación de Marx de los derechos humanos, planteada en "la cuestión judía", y a su supuesta incomprensión del rol y la naturaleza de la "emancipación política" que es correlativa a la emergencia del Estado moderno.

1 A lo largo del texto, las citas tomadas de textos en otros idiomas son de traducción propia. 
Si bien Marx tiene razón, para Lefort, en denunciar que detrás del derecho moderno y de los principios de libertad e igualdad se encuentran ocultas relaciones de opresión, sin embargo, no comprendería el nivel específico de la democracia y el Estado moderno.

[...] no se advierte que la delimitación de una esfera de lo político va acompañada de un nuevo modo de legitimación, no sólo del poder, sino de las relaciones sociales como tales. La legitimación del poder se funda en el pueblo; pero a la imagen de la soberanía popular se le une la de un lugar vacío, imposible de ocupar y del que quienes ejercen la autoridad pública no podrían apropiarse. La democracia alía estos dos principios contradictorios: uno, que el poder emana del pueblo; otro, que ese poder no es de nadie (LEFORT, 1990, p. 42-43).

Marx reduciría los derechos del hombre a una simple ilusión social: una "igualdad" formal que disimula la desigualdad económica real. La ilusión de los derechos humanos, en tanto derechos de los miembros individuales de la sociedad civil, es correlativa y complementaria de la "ilusión política" de un Estado separado como ámbito exclusivo de la política fundado sobre la ciudadanía, es decir, sobre la abstracción de las determinaciones sociales reales de los sujetos. "En otras palabras, la política y los derechos del hombre constituyen [en Marx] dos polos de una misma ilusión" (LEFORT, 1990, p. 16).

Para Lefort los derechos humanos no son "puramente formales ni destinados a disimular un sistema de dominación: vemos investirse en ellos una lucha real contra la opresión” (LEFORT, 1990, p. 10). El análisis respecto al rol y el valor de los derechos humanos se integra en la comprensión más general sobre la naturaleza de la democracia y el Estado moderno los cuales son, para este autor, la expresión de un proceso inédito de reconstitución de las relaciones sociales.

En esta línea, agrega Laclau en "Nuevas reflexiones sobre la revolución de nuestro tiempo":

Nuestra tesis es que los discursos igualitarios y los discursos sobre los derechos juegan un papel fundamental en la reconstrucción de las identidades colectivas. A comienzos de este proceso, en la Revolución Francesa, el espacio público de la ciudadanía fue el dominio exclusivo de la igualdad, en tanto que las desigualdades no fueron cuestionadas en la esfera privada. Ahora bien, como Tocqueville lo entendió claramente, una vez que los hombres aceptan la legitimidad del principio de igualdad 
en una esfera, intentarán extenderlo a todas las otras esferas de la vida. De tal modo, una vez que las dislocaciones generadas por la expansión capitalista se generalizaron, cada vez más sectores construyeron la legitimidad de sus demandas en tomo de los principios de igualdad y libertad (LACLAU, 2000, p. 143).

Y especifica, en relación a las consecuencias de ello sobre la relación entre la revolución democrática y liberalismo:

Si la democratización radical de la sociedad emerge de una variedad de luchas autónomas que son sobre determinadas por formas de articulación hegemónica, si, además, todo depende de una proliferación de espacios públicos de argumentación y decisión por la que los agentes sociales son crecientemente capaces de asumir la gestión de sus propios intereses, entonces resulta claro que este proceso no pasa por un ataque directo a los aparatos del Estado, sino que implica la consolidación y reforma democrática del Estado liberal. El conjunto de sus principios constitutivos - la división de poderes, el sufragio universal, el sistema multipartidista, los derechos civiles, etc. - deben ser defendidos y consolidados. Es dentro del marco de estos principios básicos de la comunidad política que es posible hacer avanzar el amplio arco de las reivindicaciones democráticas actuales (desde los derechos de las minorías nacionales, raciales y sexuales, hasta la propia lucha anticapitalista) (LACLAU, 2000, p. 144).

Por último, para Laclau esto conlleva una resignificación del concepto mismo de emancipación en clave de extensión y radicalización de luchas democráticas, de modo que las luchas "no tienen un punto final de llegada en el logro de una sociedad plenamente liberada. Siempre habrá antagonismos, luchas y parcial opacidad de lo social; siempre habrá historia" (LACLAU, 2000, p. 145). Laclau, en resumen, piensa la emancipación como un campo de trabajo abierto, donde intervienen sujetos indefectiblemente plurales y que es irreductible a toda escatología histórica que imagine un mundo más allá de la historia donde ya no existan antagonismos ni conflicto.

\section{Honneth: progreso moral y eticidad moderna}

En "La lucha por el reconocimiento", Axel Honneth analiza la "gramática moral" de los conflictos sociales. Los filósofos modernos presupondrían un sujeto fundamentalmente movido por necesidades de tipo egoísta. Partiendo de Georg W. 
F. Hegel y George H. Mead, en cambio, Honneth intenta desplegar una lectura del conflicto centrada en cuestiones morales. "Ambos pensadores han dado una interpretación de la lucha social, en la que ésta puede devenir una fuerza estructurante del desarrollo moral de la sociedad" (HONNETH, 1997, p. 115). Esto significa tanto que los conflictos pueden reconstruirse en torno a pretensiones de reconocimiento, como que la propia naturaleza moral de la sociedad se desarrolla a partir de la lucha.

Honneth se centra en el derecho y la estima social como esferas de reconocimiento recíproco donde se pone de manifiesto un desarrollo moral. El reconocimiento recíproco entre sujetos de derecho "depende de premisas de principios morales universalistas", que sin embargo se actualizan específicamente con el pasaje a la época moderna. "Con la transición a la época moderna, los conceptos fundamentales post-convencionales (...) insisten en el derecho válido y lo subordinan a las coerciones fundantes, que están ligadas con la idea de una compatibilidad racional acerca de normas discutibles" (HONNETH, 1997, p. 135).

Las sociedades tradicionales se caracterizan por la "autoridad inmediata de las tradiciones morales" (HONNETH, 1997, p. 135) donde el derecho se funde con la "valoración social que se le da al miembro singular de la sociedad en un estatus social" (HONNETH, 1997, p. 136). La modernidad desplaza las valoraciones de estatus como criterio del reconocimiento. Retroceden las posiciones sociales jerarquizadas estamentalmente. Ahora, en cambio, "los derechos individuales se liberan de las concretas esperas de función, ya que (...) deben atribuirse a todo hombre en tanto que ser libre" (HONNETH, 1997, p. 136). Los individuos pueden ahora orientar sus vidas en un marco "postconvencional" (no determinado directamente por la tradición) y poseen todo el mismo reconocimiento universal y básico en tanto que personas.

El derecho postconvencional no es estático sino que experimenta una dinámica histórica de "ampliación acumulativa" mediante la cual "el perímetro de las cualidades generales de una persona moralmente responsable paulatinamente se ha incrementado" (HONNETH, 1997, p. 141). Bajo la presión de las luchas por el reconocimiento, los derechos universales adscriptos a la persona se incrementaron acumulativamente, incluyendo "derechos liberales de libertad, derechos políticos de participación y derechos sociales al bienestar” (HONNETH, 1997, p. 141). Esta ampliación de derechos es "forzada desde abajo" (HONNETH, 1997, p. 143) por luchas estructuradas moralmente en términos de reconocimiento. "Cada nueva clase 
de derechos fundamentales siempre se ha forzado históricamente con argumentos que se referían implícitamente a la exigencia de una plena calidad de socio dentro de la comunidad" (HONNETH, 1997, p. 143).

Honneth atribuye un rol progresivo a la "lucha que la burguesía, en los umbrales de la modernidad, comenzó a librar contra las representaciones feudales de los nobles" (HONNETH, 1997, p. 153). Con la transición a la modernidad se despliegan la ampliación de derechos y la universalización de la dignidad personal. La época moderna, producto de la lucha de la burguesía contra el feudalismo y que dio paso al reconocimiento del derecho igual y libre, constituye por lo tanto, el horizonte social-normativo del planteo de Honneth.

Honneth recupera la diatriba de Hegel contra la moralidad kantiana abstracta, para reactualizarla en el marco de una disputa con teorías formalistas de la justicia como la de John Rawls o Jürgen Habermas. Rescata, en este marco, la noción de eticidad, que se refiere al "ethos encarnado en un mundo de la vida particular" y no se limita "a la autonomía moral del hombre, sino a las condiciones de su autorrealización” (HONNETH, 1997, p. 203). Con la sociedad moderna emerge una "eticidad democrática postradicional" (HONNETH, 1997, p. 211). En "El derecho a la libertad" retoma la problemática de la eticidad concreta y su articulación con las pretensiones universalistas del derecho, cuestionando la escisión entre filosofía política puramente normativa y análisis de la sociedad meramente descriptivo. Honneth enfrenta esta situación mediante una vuelta a Hegel y su intento, plasmado en la "Filosofía del derecho", por reconciliar los planos normativo y descriptivo. Esto supone una normatividad no puramente formal, sino atenta a las peculiaridades de la sociedad moderna, articulada en una "reconstrucción normativa" (HONNETH, 2014 , p. 6) de las instituciones existentes, evitando tanto la teoría social neutra como la filosofía política pura.

En el marco anterior, Honneth plantea una recuperación parcial y crítica de Marx. En los trabajos de juventud, Marx partiría de un concepto de trabajo cargado normativamente, incluyendo una dimensión de reconocimiento. Este planteo, sin embargo, no es solvente debido a su apuntalamiento en una ontología expresiva de la esencia humana, de cuño feuerbachiano (HONNETH, 1997, p. 176-178). En cambio, en "El capital", Marx abandonaría la "unilateralidad estético-productivista" de su juventud (HONNETH, 1997, p. 179), para pasarse a un planteo de fuertes tonos economicistas. En la madurez, en efecto, Marx recaería en el utilitarismo de las corrientes dominantes en la filosofía política de su época, interpretando la lucha de clases como un conflicto por intereses económicos donde la "lesión de pretensiones 
morales" posee un lugar secundario (HONNETH, 1997, p. 180). Al omitir las dimensiones morales del conflicto social e ignorar el potencial emancipador de la modernidad ética, el Marx maduro sería incapaz de formular una teoría social crítica adecuada a la dinámica efectiva de los conflictos sociales.

En "Freedom's Right" hay también una relación dialógica con Marx, de connotaciones más ambiguas. Honneth parte de considerar que el mercado presupone estructuras de reconocimiento, en tanto "no puede ser comprendido como un sistema 'libre de normas" (HONNETH, 2014, p. 191). Esas estructuras, sin embargo, no son realizadas de manera adecuada (o completamente adecuada) en la forma efectivamente existente del mercado, entre otras cosas porque los trabajadores no tienen otra opción que la de vender su fuerza de trabajo y por lo tanto no son "socios contractuales igualitarios" con respecto a la clase dominante (HONNETH, 2014, p. 195), viéndose además sometidos a explotación. La división en clases distorsiona la estructura moral de reconocimiento, pero no por eso el mercado es como tal inadecuado desde un punto de vista moral. Puesto que "no parece haber alternativas prácticas al sistema económico del mercado" es preciso trasladar el planteo de Marx al de Hegel. En este nuevo planteo, se puede comprender los problemas de la explotación y el contrato forzado como "desviaciones de las normas subyacentes al sistema de mercado" (HONNETH, 2014, p. 196). El mercado, en síntesis, encierra formas de dominación, pero éstas pueden ser abordadas inmanentemente a partir de estructuras de reconocimiento. Esta solución inmanente supone la intervención del gobierno en la economía (HONNETH, 2014, p. 223) y la resistencia moralmente articulada de las clases populares, que politizó el análisis del mundo del trabajo (HONNETH, 2014, p. 227). La crítica social de Marx es cuestionada por partir de una visión economicista de la lucha social (que desconoce su dimensión moral) y por atribuir la explotación y la compulsión a trabajar al mercado como tal, sin confrontarla con las formas subyacentes de moralidad plasmadas en éste. Recupera, sin embargo, el "problema Marx" entendido como la necesaria crítica a la explotación entre clases, aunque reformulándolo en busca de soluciones que no cuestionen al mercado como tal.

El autor trata de formular una teoría crítica de la modernidad trazando lo que podríamos llamar un horizonte emancipatorio inmanente. La suya no es una teoría global de la dominación social, porque considera al derecho y la moral modernos como fundamentalmente correctos, esto es, como formas sociales instituidas que realizan principios universalistas. Para Honneth, es posible criticar aspectos puntuales 
de la eticidad moderna, pero no a esa eticidad como tal. Ésta, sin embargo, no es sólo un marco dado rígido, sino que posee dinamismo. Los conflictos por el reconocimiento propulsan el desarrollo moral de la sociedad. Esa dinámica, empero, no impugna la modernidad ética de conjunto, sino que enriquece su contenido, en un movimiento de diferenciación cualitativa y ampliación cuantitativa. Honneth concibe la eticidad moderna como fundamentalmente incompleta, abierta a un proceso de desarrollo que es propulsado a través de las experiencias negativas de lucha y conflicto ${ }^{2}$.

\section{El debate de la derivación: una introducción}

A continuación vamos a reconstruir la derivación del Estado moderno de las relaciones sociales capitalistas, tal como es desplegada por Antoine Artous. El llamado "debate de la derivación del Estado" se dio fundamentalmente en Alemania a partir de los años 60 (véase PIVA y BONNET, 2017). El punto de partida de este debate es un análisis de la especificidad histórica del Estado capitalista o moderno, que estructura por primera vez un poder público separado de la sociedad, compuesto por funcionarios sin lazos directos con la clase dominante y que no son controlados por ella en forma inmediata. Estos autores buscaron pretenden derivar de la "anatomía de la sociedad burguesa” (MARX, 1989, p. 7) las particularidades históricas del Estado moderno. Mientras que las sociedades precapitalistas se basan en relaciones de dominación personal, el capitalismo se funda en un tipo de relación social objetiva, abstracta y anónima. El intercambio generalizado como forma del nexo social supone la igualdad e independencia personal de los particulares en la esfera de la circulación (HIRSCH, 2017). La explotación capitalista está organizada a partir de la relación salarial y el contrato de trabajo, que presuponen la igualdad y libertad jurídicas de las partes contratantes y por ende exigen una legalidad formalmente separada de la clase dominante. En ese contexto, las relaciones capitalistas son incompatibles con las formas de poder personal o directo características de las sociedades precapitalistas y requieren de un poder público impersonal que garantice las condiciones de la reproducción y monopolice la violencia legítima que queda afuera del proceso productivo (BONNET, 2007, p. 274).

El debate de la "derivación" tuvo una cierta repercusión en Gran Bretaña, fundamentalmente con el estudio introductorio de John Holloway y Sol Picciotto

\footnotetext{
${ }^{2}$ Bert van der Brink (2011) ha aportado a la clarificación del carácter constitutivamente abierto, conflictivo y no susceptible de cierre de la eticidad moderna en un marco pluralista.
} 
(1978), que a su vez mediatizó en buena medida la recepción latinoamericana de esta corriente. Partiendo de las tesis de Hirsch, estos autores formulan un anti-estatalismo político radical. La idea de "autonomía relativa" del Estado implicaría, según ellos, "la aceptación estructuralista de la fragmentación superficial de la sociedad burguesa en estructuras relativamente autónomas" (HOLLOWAY y PICCIOTTO, 1978, p. 6). Puesto que el Estado se deriva lógicamente de la forma capital, entonces, según estos autores, no puede tener autonomía con respecto a las necesidades de la acumulación. Esta concepción de la derivación del Estado fue criticada tempranamente por Ernesto Laclau (1981). Pese a sus méritos ("pretender determinar el lugar estructural de la forma 'Estado'"), según Laclau (1981, p. 37-38) la escuela derivacionista no rompe con el enfoque clásico del Estado por el cual "el nivel económico tiene todas las virtualidades necesarias para reproducir a la sociedad capitalista". En cambio, para Laclau (1981, p. 41) se trata de mostrar "la imposibilidad de considerar el proceso de acumulación capitalista como un proceso autorregulado de contradicciones económicas".

Antoine Artous hace una recepción muy diferente de la discusión derivacionista. Comparte algunas características generales del planteo, en cuanto construye una teoría históricamente determinada del Estado moderno, ligada con las peculiaridades estructurales del nexo social en el capitalismo. Sin embargo, el autor no deduce, a partir de la vinculación formal y sistemática entre Estado y capital, que la acción e intervención del Estado redunde forzosamente en la mera reproducción de las relaciones sociales capitalistas. Artous modula el debate de la derivación para mostrar dos tesis fundamentales: primero, que el Estado moderno está asociado estructuralmente a las relaciones de producción capitalistas, pero a la vez aparece como ámbito de condensación y estructuración jurídica de la lucha de clases. La instancia estatal aparece como campo estratégico de disputa donde la lucha de clases se organiza y coagula. Segundo, las formas jurídicas modernas, ligadas sistemáticamente a la dominación de clase de la burguesía, sin embargo también estructuran las luchas emancipatorias protagonizadas por la clase trabajadora y los movimientos sociales. Esto significa que el derecho moderno no puede reducirse a una forma de existencia de la dominación capitalista, sino que está ligado contradictoriamente a los antagonismos sociales y forma parte integral del proyecto emancipatorio de una sociedad más allá del capitalismo. Recuperando el aporte de este autor (cuyo trabajo apenas comienza a ser traducido al castellano recientemente), es posible, en suma, repensar el rol del Estado y el derecho en la tradición marxista, 
aportando a una concepción más diferenciada de estas formas institucionales y evitando, por lo tanto, su equiparación con meras formas de expresión de la dominación capitalista. Se trata de comprender la imbricación entre el Estado moderno y el capitalismo, y al mismo tiempo dar cuenta del carácter contradictorio de esta institución y su rol en los procesos de lucha de signo emancipatorio.

\section{Trabajo libre y derecho moderno en el pensamiento de Antoine Artous}

La teoría de Artous estudia las relaciones a la vez internas y contradictorias entre la forma democrática del Estado moderno y su naturaleza de clase burguesa. La burguesía como clase dominante no ejerce la explotación a través de relaciones de dominación directa o personal (como en sociedades precapitalistas) sino mediante el intercambio de equivalentes en el mercado. Esto significa que la explotación moderna o capitalista presupone que las personas se vinculen como particulares libres e iguales en el mercado. Luego, la dominación política de la burguesía debe asumir la forma de un poder público separado. Esto explica la no-homogeneidad sociológica entre el Estado moderno y la clase dominante: uno y otra mantienen una conexión estructural pero no directa, o el Estado es capitalista antes que propiamente burgués. El Estado moderno, diferenciado de las formas de soberanía precapitalistas en la medida en que se estructura como un poder político no atado a intereses "privados" inmediatos, se vincula estructuralmente con el capital. Esto funda su dependencia sistemática de las relaciones de producción vigentes, pero también da cuenta de su autonomía relativa, en la medida en que no es conceptualizable como un "instrumento" (MILIBAND, 1989, p. 5) de la clase dominante.

En segundo lugar, este planteo introduce una dimensión adicional en el análisis de la mercancía fuerza de trabajo. La existencia de trabajadores libres (desposeídos de los medios de producción, liberados de toda atadura de dominación personal y de todo lazo comunitario) es, como se sabe, una precondición histórica y lógica para la explotación capitalista. El trabajador aparece, en virtud de esta doble condición, como un individuo igual en la esfera de la circulación y como un individuo sometido al comando del capital en la esfera de la producción. Los trabajadores no son solo individuos libres en la circulación sino también sujetos de ciudadanía activa, que imponen o propulsan derechos colectivos y específicos que trascienden la interacción entre individuos abstractamente iguales. En esta dimensión de ciudadanía activa y socialmente diferenciada asumida por la clase trabajadora aparece el rol constitutivo del Estado en la lucha de clases: las relaciones de fuerza 
entre clases sociales se plasman siempre en forma política, en leyes, regulaciones y medidas sancionadas por el Estado. Éste funciona como el ámbito donde la lucha de clases coagula, institucionaliza y sanciona en un momento dado. Así, la propia relación salarial y las condiciones de explotación de la fuerza de trabajo aparecen como mediadas estatalmente y la lucha de clases se resuelve como lucha en torno al Estado y la política.

La reconsideración de la teoría marxista del Estado a partir de estos desarrollos haría posible una relación más afirmativa con las conquistas democráticas de la época moderna. Como sostuvimos en la Introducción, el marxismo enfrenta hoy desafíos intelectuales de envergadura a la hora de ofrecer una valoración más matizada de la democracia, la pluralidad y la heterogeneidad social. Artous permite revalorizar la democracia como parte integral del proyecto emancipatorio y de la crítica del capitalismo. Lejos de cualquier pretensión de sutura totalizante de lo social, el suyo es un marxismo abierto al ideario democrático y por ende mejor preparado para relacionarse con los desafíos éticos y teóricos contemporáneos.

Estos análisis permiten rediscutir la relación entre las formas jurídico-políticas modernas y la perspectiva emancipatoria socialista. Este punto ha constituido un punto ciego en la tradición marxiana. De un lado, las concepciones ortodoxas han tendido a ver las libertades jurídicas burguesas como meras formas de existencia que enmascaran un contenido diferente, a saber, la dominación de clase. Del otro lado (como en el posmarxismo) se piensa a las formas jurídicas y políticas como neutrales en términos de clase o como ajenas a la lógica del capital. Contra ambas miradas, estos estudios permiten comprender la dinámica contradictoria (de unidad y oposición) entre el derecho moderno y el capital. Esta relación contradictoria significa que el derecho y la política modernos son al mismo tiempo formas de existencia de la dominación capitalista y terreno de disputa en la lucha de clases.

\section{Estudio comparativo}

Arriba esbozamos los lineamientos de lo que podemos considerar como tres reconstrucciones de la lógica social en la modernidad que prestan especial atención a la especificidad de la democracia y el derecho. Laclau y Mouffe conceden a lo político un rol "fundacional" con respecto a lo social. No tratan de remitir las articulaciones hegemónicas a un ordenamiento social que les sería previo sino que conciben a lo político como el momento de institución de la sociedad como tal, previamente al cual la sociedad como totalidad no existe. En efecto, solo la operación hegemónica que 
reúne diversas demandas flotantes bajo un significante vacío instituye lo social como tal. La unidad de la sociedad no es entonces una estructura preexistente sino un resultado de la operación política contingente que suelda demandas heteróclitas bajo una orientación común. Sin embargo, al menos en "Hegemonía y estrategia socialista" (la formalización del planteo parece ser mayor en obras posteriores), los autores conceden que la propia lógica hegemónica cobra toda su importancia y desarrollo en la modernidad, esto es, en el tiempo de la revolución democrática preconizada por Lefort. Hay, al parecer, precondiciones históricas para la política hegemónica. Las sociedades tradicionales, por ejemplo, serían escasamente susceptible de articulación hegemónica, pues su espacio social parece estar tan suturado que no habilitaría articulaciones diferenciales.

La dimensión hegemónica de la política solo se expande en tanto el carácter abierto, no-saturado de lo social, se incrementa. En una comunidad campesina medieval, el área abierta a articulaciones diferenciales es mínima y, por lo tanto, allí no hay formas de articulación hegemónica (...). Es por esto que la forma hegemónica de la política sólo se vuelve dominante con los tiempos modernos, cuando la reproducción de diferentes áreas sociales tiene lugar en condiciones sociales permanentemente cambiantes (LACLAU y MOUFFE, 2001, p. 138, cursivas agregadas).

Laclau y Mouffe no cuestionan los orígenes de la pluralidad de demandas, a la que consideran como un punto de partida no susceptible de ulterior análisis. "La pluralidad no es el fenómeno a analizar, sino el punto de partida del análisis" (LACLAU y MOUFFE, 2001, p. 140). Sin embargo, parece que la existencia de una multiplicidad de demandas "es en sí misma un producto histórico". La revolución democrática marcaría "la mutación decisiva en el imaginario político de las sociedades occidentales" (LACLAU y MOUFFE, 2001, p. 155), produciendo el "marco" para la lógica de hegemónica (LACLAU y MOUFFE, 2001, p. 168). Hay un contexto social previo que posibilita la pluralidad de demandas: "sólo desde el momento cuando el discurso democrático pasa a estar disponible para articular distintas formas de subordinación, van a existir las condiciones para hacer posible la lucha contra distintos tipos de desigualdad" (LACLAU y MOUFFE, 2001, p. 155).

Honneth, por su parte, se basa de manera explícita en una consideración de la modernidad como forma de eticidad encarnada. Lo que Honneth llama "reconstrucción normativa de la vida ética" guarda una relación compleja con las 
instituciones efectivamente dadas en la modernidad. No es "una mera descripción de condiciones existentes" (HONNETH, 2014, p. 7) porque incluye la posibilidad de criticar esas mismas instituciones, realizando una aproximación "más selectiva, tipificada y normativa" (HONNETH, 2014, p. 8). Sin embargo, la eticidad encarnada en la modernidad gesta las condiciones de posibilidad para el desarrollo moral contemporáneo, fundado en parámetros de autonomía individual o derecho a la libertad. "En la modernidad, la demanda de justicia puede probarse legítima solamente si hace algún tipo de referencia a la autonomía del individuo" (HONNETH, 2014, p. 17). Honneth (2014, p. 18) apela a una "perspectiva teleológica" como "un elemento inevitable de la auto-comprensión de la modernidad". La ligazón entre justicia y libertad individual no es meramente una contingencia histórica, sino que "representa el resultado de un proceso de aprendizaje que duró varios siglos” (HONNETH, 2014, p. 17). La lucha por el reconocimiento es, por lo tanto, enmarcada en las condiciones históricas (que incluyen aprendizajes normativos) de la modernidad constituida, con la separación de esferas de reconocimiento (amor, estima, derecho).

En el caso de Artous, encontramos también una reconstrucción de las formas políticas de la sociedad moderna, pero que se funda lógicamente en las categorías sociales del capitalismo, en particular en la forma asumida por la relación capitalista de explotación. Para Artous, la dominación de clase en el capitalismo no es simplemente una variante nueva de las dominaciones de clase preexistentes, sino que implica un cambio de forma. En efecto, la burguesía se relaciona de modo específico con la igualdad y la libertad jurídicas que regulan y posibilitan la esfera del intercambio. Es en esta esfera que se hace posible el contrato de trabajo, que habilita la explotación a partir de una relación contractual entre partícipes libres e iguales. La explotación moderna, en cuanto mediada por la esfera de circulación y el contrato laboral, tiene una forma jurídica y presupone la igualdad y la libertad entre los particulares. Los individuos confrontados como tales en el contrato de trabajo no pueden vincularse bajo la forma de la dominación política personal. Luego, la explotación capitalista exige lógicamente un Estado político separado, no "anclado" en posiciones sociales de tipo estamental, que ejerza un poder público anónimo y vigile la libertad e igualdad formales entre individuos.

La figura del moderno trabajador libre articula a la vez la igualdad y la dominación, la autonomía y la heteronomía. Esto hace posible una crítica inmanente de la forma moderna de explotación y dominación, que cuestione la exclusión de la 
democracia del mundo de la economía y el trabajo. En efecto, el capitalismo pone la contradicción en movimiento por la cual sanciona una forma de libertad e igualdad y, al realizarlas, también las desmiente, poniéndolas como dominación y explotación. Esto hace posible una crítica inmanente de las formas jurídicas del capitalismo, que son a la vez las portadoras de aspiraciones emancipatorias y el modo que asume la dominación social.

Artous, a su vez, construye una teoría embrionaria sobre las formas de acción colectiva bajo la legalidad capitalista sobre la base de la organización y el conflicto de la clase trabajadora. Los trabajadores organizados trascienden el derecho igual individual para plantear formas jurídicas que, sin desandar las conquistas liberadoras de la abstracción jurídica moderna y el poder público, tienen sujetos colectivos anclados en posiciones sociales preexistentes y diferenciadas. Esto permite reconstruir la larga historia de conflictos de los movimientos sociales en la modernidad a partir de las formas jurídicas y su contestación democrática, excediendo los límites de cualquier individualismo jurídico.

La concepción de Artous, creemos, permite dar cuenta de la articulación sistemática entre las luchas democráticas modernas y las formas sociales impuestas por el capital. Esto ilumina la "contradicción entre capitalismo y democracia": por un lado, la democracia moderna se articuló en los términos del derecho abstracto y el Estado político separado, que es un corolario lógico de la dinámica del capital. Por el otro, la forma democrática es capaz de trascender los contenidos capitalistas que reviste, informando las luchas sociales emancipatorias. Su teoría se muestra más comprehensiva que las de Laclau, Mouffe o Honneth. En efecto, estos pensadores reconstruyen la dinámica efectiva de las luchas sociales modernas (en términos de demandas democráticas o ampliaciones de derechos), pero no elaboran de modo sistemático el vínculo entre la lógica del capital y el derecho democrático moderno. Sus planteos permanecen en el análisis de las formas políticas, sin reconstruir de modo global y articulado la imbricación entre estas formas y la dinámica social del capital en su generalidad.

\section{La ciudadania moderna y la emancipación social}

Toda una problemática estratégica y programática se dibuja en torno a una concepción orgánica, o "fusional" (en términos de la fusión de los elementos diversos en una totalidad) de la emancipación. Esto es, tanto a la perspectiva de disolución final de la política en la producción social, como a la tentativa, de más corto plazo, de unificación de las tareas administrativas y el poder político. Marx explica en "La 
guerra civil en Francia", que "la Comuna no había de ser un organismo parlamentario, sino una corporación de trabajo, ejecutiva y legislativa al mismo tiempo" (MARX, 2007, p. 67), refiriéndose a la fusión de las tareas administrativas con los órganos del poder político. Este enfoque se proyecta en la problemática soviética que aparece a partir de la revolución de octubre. En las tesis para el primer Congreso de la Komintern, Lenin $(1919, \mathrm{~s} / \mathrm{p})$ define el poder soviético tanto por la elección sobre la base de "unidades de trabajo", como por la fusión del poder ejecutivo y legislativo. Gramsci, por su lado, tomando como referencia la experiencia de los consejos obreros de Turín, define el consejo de fábrica como la base y el fundamento del estado proletario, cuyos miembros dejan de ser ciudadanos abstractos, para ser productores no "alienados" de la vida social. Con los consejos, la clase obrera "asienta de nuevo la fábrica (...) como la forma en la cual la clase obrera se constituye en cuerpo orgánico determinado, como célula de un nuevo Estado, el Estado obrero, y como base de un nuevo sistema representativo, el sistema de los Consejos" (GRAMSCI, 1920, p. 126).

El objetivo de estos revolucionarios es, entonces, cuestionar la abstracción ciudadana para disolver la ciudadanía en lo social. Suponiendo que por este movimiento comienza a reconstruirse una reunificación de una serie de dimensiones "separadas" de la vida social en el capitalismo: el estado y la sociedad civil, el producto y el ciudadano, el trabajo y el tiempo libre, el individuo y la comunidad. Citemos un texto de Bensaïd que resume claramente esta concepción

\begin{abstract}
Al volverse el epicentro del poder, la asociación de los productores en su lugar de trabajo trastorna al conjunto de la estructura social, anula la escisión entre el estado y la sociedad civil. La empresa en donde reside la estructura de base del nuevo poder ya no puede ser una empresa, al igual que el Estado proletario, según la expresión de Engels, ya no es "un Estado en sentido propio" (...) Porque definir la colectividad de los productores como célula de base de la soberanía proletaria no significa localizar la base de ese poder en los lugares de producción, sino modificar de fondo los tabicamientos sociales establecidos por el capitalismo (BENSAÏD, 1976, p. 239).
\end{abstract}

El trabajo ya no es una actividad separada, "se convierte en la trama socializada de las nuevas relaciones sociales, en las que se superan las separaciones entre la esfera del trabajo y del no - trabajo" (BENSAÏD, 1976, p. 239). Este tipo de análisis muestran familiaridad con la mirada productivista que despliega Engels en el 
“Anti-Dühring” (2003, p. 105), por la que considera que las fuerzas productivas portan un potencial socializador solo contenido por la propiedad burguesa y la anarquía del mercado. El mismo Lenin, en "El Estado y la revolución", prolonga este enfoque cuando postula que las grandes fábricas y la industria desarrollada por el capitalismo constituyen el terreno sobre el cual puede desplegarse la extinción del Estado luego de la conquista del poder por el proletariado (LENIN, 1973, p. 134). Se ve aquí con claridad que, en este enfoque, la cuestión del lugar del trabajo y la producción social y la concepción de la democracia y el Estado forman una unidad.

Si abandonamos una concepción orgánica y fusional de la emancipación, no es posible ya pensar un poder público que esté completamente unificado con la producción, ni que se reduzca a funciones técnicas o de dirección de los procesos productivos. Es inevitable entonces postular la existencia de un poder público en tanto poder o Estado político separado (ARTOUS, 2016a). Más concretamente, esto quiere decir que el poder público discurrirá sobre la base de ciudadanía abstracta (moderna), y no en su anulación a partir de una fusión del lugar del ciudadano y el productor.

La emergencia del Estado moderno es correlativo de un espacio social históricamente inédito: el de un "poder público" que rompe con lo que Max Weber llama "patrimonialización de las relaciones de soberanía”, es decir, un poder político que no es propiedad de un grupo social o individuo, y se funda en la soberanía popular, por fuera de jerarquías divinas. La lucha contra el Estado capitalista no puede ser, entonces, el intento de reducir este nivel de la práctica social a una mítica unidad perdida de la sociedad, que supere todas las divisiones, ya no solo de clase, sino también entre sociedad civil y Estado o entre productor y ciudadano. Se trata de profundizar y democratizar, contra el capitalismo, el carácter público del "poder público”, despojándolo ya no de su dependencia de relaciones patrimoniales o jerarquías divinas, sino de su subordinación al poder del capital.

\section{Democracia y producción social más allá de la concepción orgánica}

El capitalismo entra en contradicción con la democracia porque tiende permanentemente a restringir el ejercicio de la ciudadanía al plano estricta o limitadamente político. No hay proyecto socialista, entonces, que no implique trastornar esta restricción que el capital impone a la democracia. La experiencia del siglo muestra que un control democrático de la economía no puede reducirse a una dirección estatal desde arriba, sin incluir un cuestionamiento a la división capitalista 
del trabajo al interior de las relaciones de producción y lo que Marx llamaba "despotismo de fábrica" (apud ARTOUS, 2016b, p. 25).

En este punto, son especialmente útiles los aportes de Ellen Meiksins Wood en "Democracy against capitalism", quien define la naturaleza capitalista del Estado representativo democrático en base a la separación entre política y economía. Al separar lo político de lo económico, la específica forma de explotación capitalista que se realiza en la esfera privatizada de la sociedad civil aparece como incuestionable. A su turno, esta neutralización de la democracia en la esfera económica posibilita la profundización sin precedentes históricos del control de la clase dominante sobre el proceso de producción. "La 'sociedad civil' ha dado a la propiedad privada y sus poseedores un comando sobre las personas y su vida diaria (...) que muchos viejos Estados tiránicos habrían envidiado" (MEIKSINS WOOD, 1995, p. 254). Al constituir una esfera separada de la política, la explotación "puramente económica" (MEIKSINS WOOD, 1995, p. 186) de la clase trabajadora aparece como algo no cuestionable. Más aún: la separación entre política y economía es condición para que la lógica del capital, en su dinámica autonomizada y ciega, se regule a sí misma contra las posibilidades de decisión democrática de las personas.

La separación entre economía y política en el capitalismo conlleva una neutralización del potencial explosivo de la democracia. Una vez que la explotación se realiza en la esfera privatizada de la economía, deja de aparecer como un problema político. Así, la propia lucha de clases puede ser reducida a una disputa "meramente" económica, al tiempo la interrogación democrática sobre la vida social es excluida de la esfera de la producción y la distribución. "La extracción de excedente deja de ser un asunto político inmediato” (MEIKSINS WOOD, 1995, p. 44). En el capitalismo, de esta manera, el conflicto de clase es "encapsulado" y "domesticado" (MEIKSINS WOOD, 1995, p. 45) dentro de los límites de la unidad productiva y la economía, donde no alcanza a cuestionar la forma y el carácter generales de la sociedad. La democracia, como surge en el marco del capitalismo, aparece mellada en su filo crítico en la medida en que las actividades puramente económicas, en cuyo marco se realiza la explotación, son constituidas como una esfera neutralizada, regida por mecanismos automáticos y no susceptible de cuestionamiento político.

Esta "despolitización" de la economía va en el sentido del papel ideológico, ya señalado por Marx, de la democracia como "soberanía ilusoria" (MARX 2003, p. 22). que oculta la división de clases. Perry Anderson formula claramente este aspecto 
central de la dominación burguesa, que prevalece incluso por sobre los avances materiales conquistados en el marco del capitalismo:

la forma general del Estado representativo - en una democracia burguesa - es ella misma la principal arma ideológica del capitalismo occidental (...) Lo que hay de nuevo en las formas de este consentimiento es fundamentalmente que éstas ejercen una suprema autodeterminación en el seno del orden social existente. No se trata, por tanto, de la aceptación de la superioridad reconocida de una clase dirigente (ideología feudal), sino de la creencia en la igualdad democrática de todos los ciudadanos en este gobierno de la nación (ANDERSON, 2018, p. 46 y 50).

En consecuencia, si una "generalización de la democracia" hacia un amplio espectro de relaciones sociales (ARTOUS, 2016a, p. 77) no puede prescindir de la ciudadanía abstracta, tampoco puede reducirse a ella. Es preciso introducir mecanismos de "democracia económica" que impugnen el "despotismo de fábrica" y quiebren la limitación de la democracia al ámbito exclusivamente "político", nervio de la dominación burguesa. En este nivel, retomar estructuras del tipo de los "consejos obreros" tiene todo su sentido. Es necesario formular, pues, formas democráticas que emerjan del seno de las unidades productivas, y no solo participen en la autogestión de las unidades productivas, sino que participen del poder político nacional. Esto obliga a pensar formas de democracia mixta (ligada a lo social y a la vez representativa), como ya propusieron los austro-marxistas en los años 20 (BENSAÏD, 2007, p. 5), en una doble problemática de la representación política que combine formas directas e indirectas, elecciones generales libres según la lógica de la ciudadanía política "abstracta", y representación de lo "social" en el seno del Estado (sindicatos, asociaciones, movimientos de mujeres), en la tradición de los consejos obreros.

\section{Conclusión}

Si Laclau, Mouffe y Honneth producen teorías de la democracia moderna capaces de describir dinámicas de conflicto, sin embargo omiten una consideración crítica de la neutralización de la democracia bajo el capitalismo. La teoría de la derivación, considerando los aportes de Artous (y sumando algunas consideraciones de Meiksins-Wood) se muestra mejor capacitada para relacionarse afirmativamente con las conquistas democráticas modernas sin por eso desconocer la neutralización de la democracia producida en el capitalismo. Esta teoría permite vincular la revolución 
democrática y el derecho postconvencional con los marcos dinámicos y conflictivos abiertos en la sociedad capitalista, dando cuenta de la "contradicción entre capitalismo y democracia”.

El derecho y la política modernos son formas de existencia de la dominación y la explotación capitalista porque ésta se realizan a través de la igualdad y libertad de los particulares en la esfera de la circulación, a su vez garantizadas por el Estado como poder público separado. Las peculiaridades del derecho moderno como derecho igual y del Estado moderno democrático, no ligado a posiciones estamentales en la sociedad, se fundan en las necesidades lógicas de la compra-venta de mercancías (incluida la fuerza de trabajo), por lo que la política y el derecho modernos son formas de existencia de la dominación de clase capitalista.

Al mismo tiempo, y contradictoriamente con lo anterior, la política y el derecho moderno son palancas de la lucha de clases y guardan una relación de continuidad parcial con el proyecto emancipatorio del socialismo. Primero, el doble estatus del trabajador moderno (libre de relaciones de dominación personal, desposeído de los medios de producción) funda un doble tipo de individuación. De un lado, el trabajador moderno se individualiza como individuo efectivamente libre e igual; del otro, como trabajador parcelario sometido al comando del capital. Esto significa que la propia sociedad burguesa traiciona la libertad e igualdad que proclama en la misma forma en que las realiza, puesto que la libertad (en la esfera de la circulación) se ve desfigurada como forma de existencia de la dominación (que se transparenta en el ámbito de producción y el "despotismo de fábrica"). La doble figura del trabajador libre se articula contradictoriamente, realizando en una misma lógica social a la vez la libertad, la igualdad, la dominación y la explotación.

La lucha de clases se cristaliza en formas jurídicas y políticas sobre la base de la acción colectiva de los trabajadores como sujeto colectivo cuyas conquistas se realizan en la forma de derechos y regulaciones sancionados por el Estado. Esta dimensión excede el derecho igual entre individuos en la circulación y remite, en cambio, a los procesos de ampliación de derechos de parte de la ciudadanía activa. En este plano, la lucha de clases (y luego diferentes "movimientos sociales" que pugnan por conquistas políticas y jurídicas) se institucionaliza en torno al Estado y sus regulaciones. El Estado aparece, pues, no sólo como el garante de la explotación capitalista sino también como el ámbito en que las relaciones de fuerza sociales se condensan en un momento histórico dado. 
Si bien, llamativamente, se encuentran pocas referencias en la obra de Artous, existe un precedente teórico evidente a esta concepción del Estado como "campo estratégico de disputa" en el último Poulantzas. En Estado, poder y Socialismo, Poulantzas defendió la posibilidad de articular la lucha en el seno del aparato de Estado con la movilización de masas extraparlamentaria. Para el autor griego, se trata de articular:

Una lucha interna dentro del Estado, no simplemente en el sentido de una lucha encerrada en el espacio físico del Estado, sino de una lucha situada en el terreno del campo estratégico que es el Estado, lucha que no trata de sustituir el Estado burgués por el Estado obrero a base de acumular reformas, de tomar uno a uno los aparatos del Estado burgués y conquistar así el poder, sino una lucha que es, si quieres, una lucha de resistencia, una lucha de acentuación de las contradicciones internas del Estado, de transformación profunda del Estado. Y al mismo tiempo, una lucha paralela, una lucha fuera de los aparatos y las instituciones, engendrando toda una serie de dispositivos, de redes, de poderes populares de base, de estructuras de democracia directa de base, lucha que, aquí también, no puede estar dirigida a la centralización de un contra-Estado del tipo de doble poder, sino que debe articularse con la primera (POULANTZAS, 1977, p. 5).

Estos análisis permiten romper a la vez con el anti-estatalismo ingenuo de buena parte de la tradición marxiana, sin caer en cambio en ilusiones estatistas. Podemos resumir el espíritu del planteo en términos de criticar los ideales políticos y jurídicos burgueses en nombre de la realidad capitalista y a la vez criticar esa realidad, en nombre de sus propios ideales. De una parte, la igualdad y libertad proclamada en la sociedad capitalista se ven traicionadas por el despotismo de fábrica y el sometimiento del trabajo al capital. Es posible, pues, criticar la realidad social capitalista desde el punto de vista de los ideales que esa misma realidad proclama. De otra parte, la igualdad y libertad se realizan efectivamente en la sociedad capitalista, posibilitando la explotación y la dominación de clase burguesas que se realizan a través de la circulación mercantil. Es posible, pues, criticar estos mismos ideales por su función ideológica, que oculta la dominación efectiva en la sociedad burguesa. La crítica, así, analiza la contradicción y relación interna entre las formas políticas y jurídicas modernas y la lógica del capital. Esto ilumina tanto el potencial emancipatorio de la política moderna, como su imbricación dialéctica con la dominación social en el capitalismo. 
Ya no podemos pensar que la sociedad que se asome luego de superada la explotación capitalista será la asociación de productores libres, que reducen el "poder público" a una mera administración técnica de los procesos productivos, aboliendo toda superestructura política en sentido fuerte (Estado, derecho). Por el contrario, la emancipación pasa por radicalizar las potencialidades presentes en la emergencia de esa práctica social inédita consistente en valorar en común el porvenir común, por fuera de toda relación de soberanía patrimonial o jerarquía divina. No se trata de abolir la política en lo social sino de extender el campo democrático y contingente de la política por sobre el automatismo ciego de lo social.

- Facundo Nahuel Martín é Doutor em Filosofia, pela Universidad de Buenos Aires e Pós-doutorando, com bolsa do Conselho Nacional de Investigações Científicas e Técnicas. (CONICET). E-mail: facunahuel@gmail.com.

Martín Ariel Mosquera é Doutorando, pela Universidad de Buenos Aires, com bolsa do Conselho Nacional de Investigações Científicas e Técnicas. (CONICET). E-mail: martinmosquera01@, gmail.com.

\section{Referências}

ABENSOUR, Miguel. La democracia contra el Estado. Buenos Aires: Colihue, 1998.

ANDERSON, Perry. Las antinomias de Antonio Gramsci. Madrid, Akal, 2018.

ARTOUS, Antoine. Marx, el Estado y la política. Barcelona: Sylone, $2016 \mathrm{a}$.

ARTOUS, Antoine. Retorno sobre algunas cuestiones y dificultades. In: ARTOUS, Antoine et al.

Naturaleza y forma del Estado capitalista. Buenos Aires: Herramienta, 2016b, p. 19-56.

BENSAIID, Danie. Le revolution et le pouvoir. Paris: Stock, 1976.

BONNET, Alberto. Los debates sobre la derivación y la reformulación del estado en Alemania y Gran

Bretańa. In: MABEL, Thwaites Rey (Org.). Marxismo y Estado. Un siglo y medio de debates. Buenos Aires: Prometeo, 2007, p. 135-152.

ENGELS, Friedrich. Anti-Dühring. Buenos Aires: El progreso, 2003.

GRAMSCI, Antonio. El consejo de fábrica. L’Ordine Nuovo: Turín, p. 123-127 1920. Disponible en: <http://www.gramsci.org.ar/1917-22/19-consejo-fabrica.htm>. Acceso el: 11 mar. 2019. 
HIRSCH, Joachim. El aparato de estado y la reproducción social: elementos de una teoría del estado burgués. In: PIVA, A; BONNET, A. (Orgs.). Estado y capital. El debate sobre la derivación del Estado. Buenos Aires: Ediciones Herramienta, 2017, p. 509-589.

HOLLOWAY, John; PICCIOTO, Sol. State and Capital: A Marxist debate. Londres: Edward Arnold, 1978.

HONNETH, Axel. Moral Development and Social Strugle: Hegel's Early Social-Philosophical Doctrines. In: HONNETH, Axel et al. (Orgs.). Cultural-Political Interventions in the unfinished Project of the Enlightenment. Cambridge: MIT Press, 1992, p. 197-218.

HONNETH, Axel. La lucha por el reconocimiento. Por una gramática moral de los conflictos sociales. Barcelona: Crítica, 1997.

HONNETH, Axel. Reificación. Un estudio en la teoría del reconocimiento. Buenos Aires: Katz, 2007.

HONNETH, Axel. Freedoms right. The Social Foundations of Democratic Life. Cambridge: Polity, 2014

LACLAU, Ernesto. Teorías marxistas del Estado: debates y perspectivas. In: LECHNER, Norbert (Org.). Estado y política en América Latina. México D. F.: Siglo Veintiuno, 1981, p. 25-59. . Emancipación y diferencia, Buenos Aires: Ariel, 1996.

Nuevas reflexiones sobre la revolución de nuestro tiempo. Buenos Aires, Nueva Visión,

2000.

On Populist Reason. Londres y Nueva York: Verso, 2005.

LACLAU, Ernesto; MOUFFE, Chantal. Hegemony and socialist strategy. Londres y Nueva York, Verso: 2001.

LEFORT, Claude. La invención democrática. Buenos Aires, Nueva Visión, 1990.

LEFORT, Claude. Derechos del hombre y política. Apuntes Filosóficos, v. 16, n. 30, 2007.

LENIN, Vladimir. Tesis sobre la democracia burguesa y la dictadura del proletariado. Petrogrado: Actas del Primer Congreso de la Internacional Comunista, 1919. Disponible en: <https://www.marxists.org/espanol/comintern/1919/4_iii.htm>. Acceso el: 11 mar. 2019.

LENIN, Vladimir. El Estado y la revolución. In: LENIN, Vladimir. Obras escogidas, Moscú: Editorial El Progreso, 1973.

MARX, Karl. Contribución a la crítica de la economía política. Buenos Aires: Editorial Progreso, 1989.

MARX, Karl. Páginas Malditas. Buenos Aires, libros de Anarres, 2000.

MARX, Karl. La guerra civil en Francia. Madrid, Fundación Federico Engels, 2007.

MILIBAND, Ralph. The State in Capitalist Society. Basic Books: Nueva York, 1989.

MEKSKINS WOOD, Ellen. Democracy against Capitalism. Cambridge: Cambridge University Press, 1995.

PIVA, Adrián; BONNET, Alberto. Estado y capital. El debate sobre la derivación del Estado. Buenos Aires: Ediciones Herramienta, 2017.

POULANTZAS, Nicos. El Estado y la transición al socialismo,1977. Disponible en: <http://vientosur.info/IMG/pdf/Entrevista_Weber-Poulantzas.pdf>. Acceso el: 15 mar. 2019.

POULANTZAS, Nicos. Estado, poder y socialismo. Madrid, Siglo Veintiuno, 1980.

ROGGERONE, Santiago. ¿Alguien dijo Crisis del marxismo? Axel Honneth, Slavoj Žižek y las nuevas teorías críticas de la sociedad, Buenos Aires, Prometeo, 2018. 
VAN DER BRIK, Bert. Recognition, Pluralism and the Expectation of Harmony: Against the Ideal of an Ethical Life «Free from Pain. In: PETHERBRDIGE, David (ed.) Axel Honneth: Critical Essays. Boston: Brill, 2011, p. 155-176.

WHITEBOOK, Joel. Perversion and Utopia: A Study in Psychoanalysis and Critical Theory. Cambridge: MIT Press, 1995.

Texto recebido em 15 de dezembro de 2018. Aprovado em 11 de março de 2019. 